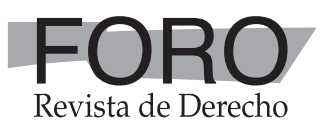

\title{
Ciudadanía republicana: deberes generales y especiales regulados desde la esfera jurídico-penal
}

Republican citizen: general and specific duty regulared from the legal-criminal sphere

\section{Vicente Vásconez Merelo}

Abogado en libre ejercicio

Ecuador

vvasconez@hotmail.es

ORCID: 0000-0002-3617-7292

DOI: https://doi.org/10.32719/26312484.2021.35.10

Fecha de recepción: 6 de mayo de 2020

Fecha de aceptación: 22 de septiembre de 2020 


\section{RESUMEN}

En esta obra el autor pone de manifiesto que un modelo republicano de gobierno exige una participación activa de todos los ciudadanos, pues la democracia no debe ser entendida solo en términos de participación, sino también en términos deliberativos. Además, bajo esta misma concepción, los ciudadanos de una república no solo tienen derechos, sino que también poseen obligaciones que son impuestas por el gobierno de turno; algunas de ellas, desde una esfera jurídicopenal, son de carácter general (no matar) y otras son destinadas a un número cerrado de personas (funcionarios públicos). Por tanto, el propósito del presente artículo se encamina a profundizar las nociones de democracia y libertad que le son inherentes a un modelo republicano de gobierno, seguido de un estudio sobre los deberes generales y específicos de determinados ciudadanos y, en especial, se analizará lo relativo al deber cívico de "prudencia en el quehacer público" que trae aparejado una serie de consecuencias por incumplimiento. Así pues, una vez que se haga un barrido doctrinal y jurisprudencial de los temas aludidos, será posible concluir que en un modelo republicano de gobierno la democracia deberá ser de carácter deliberativa, la libertad tendrá que ser entendida en términos de "no dominación", y las consecuencias jurídicas por incumplimiento de los deberes generales y especiales deberán apegarse en la medida de lo posible a la idea de justicia restaurativa.

PALABRAS ClAVE: corrupción, deliberación, democracia, justicia, libertad, pena.

\section{ABSTRACT}

On this paper the author reveals that a republican government model demands an active participation of their citizens, democracy must not be just understood in participation terms but Also deliberative ones. Also, under the same idea, citizens not only have rights, but also have obligations that are imposed by the government from that moment, some of them, from a legal-criminal sphere, some obligations are general (do not kill) and others are aimed at a closed number of people (civil servant). Therefore, the purpose of this work is aimed at deepening the notions of democracy and freedom that are inherent in a republican model of government, continued from a study on the general and specific duties of certain citizens and, in particular, it will analyze what is related to the civic duty of "Prudence of public servants" that brings with it a series of consequences for non-compliance. In this way, once a doctrinal and jurisprudential review of the issues avoided is prepared, it will be possible to conclude that in a republican model of government democracy must be deliberative, freedom will have to be understood in terms of "nondomination", and the legal consequences for breach of general and special duties should adhere as far as possible to the idea of restorative justice.

KEYWORDS: corruption, deliberation, democracy, justice, freedom, punishment. 


\section{INTRODUCCIÓN}

$\mathrm{E}$ s reconocido por la doctrina que un modelo republicano es caracterizado por el rol protagónico que ejercen sus ciudadanos, y aquel protagonismo debe ir direccionado al bienestar de la comunidad, incluso por encima de ciertos intereses individuales. Mas, sin embargo, una condición necesaria para cumplir este objetivo será que el Estado inculque virtud cívica en sus ciudadanos y esta tarea deberá ser congruente con una noción de libertad que asegure los cimientos de la democracia y el respeto a la dignidad del hombre, por lo que — según entiendo - la norma jurídica sería el único medio idóneo para asegurarle al ciudadano protección frente a sus congéneres y frente al Estado. Pese a ello, no se debe inobservar que allí donde la norma ofrezca un mar de libertades, también individualizará islotes de obligaciones jurídicas con sus respectivas consecuencias por incumplimiento que, según desde la esfera jurídica en que se analice las conductas, podrían existir sanciones desde las más leves, como una mera amonestación, hasta las más graves, como son las penas privativas de libertad.

Además, se ha de sostener que la concepción republicana de trabajo conjunto para bienestar conjunto es irreconciliable con la corrupción, entendida esta como la primacía de los intereses individuales por encima de los comunitarios; consecuentemente, se apuntalará la idea de que un modelo republicano impone obligaciones generales para una abstracción de ciudadanos y ciertas obligaciones especiales para un número cerrado de individuos a raíz de las actividades en que se desenvuelven, como por ejemplo la administración pública (se hará una breve mención dogmática de los tipos penales de corrupción desde la legislación argentina y ecuatoriana). Por último, será de especial interés para los efectos de la presente investigación analizar cómo deberían encararse, y bajo qué apercibimientos jurídicos, las conductas que denoten irreverencia por los deberes especiales prescritos normativamente, por lo que una revisión en retrospectiva de las teorías de la pena nos marcará la hoja de ruta para el último capítulo.

\section{LA CIUDADANÍA EN TÉRMINOS REPUBLICANOS: UNA NOCIÓN DE LIBERTAD}

Enseñan Ovejero, Martí y Gargarella que ser ciudadano de una república “implica asumir un compromiso en relación con los intereses fundamentales de la sociedad en su conjunto, lo cual a su vez supone la existencia de ciertas cualidades de 
carácter propias de cada uno de los miembros de la comunidad". ${ }^{1}$ Por tanto, un comportamiento caracterizado por la pasividad y desatención de los ciudadanos respecto de los intereses comunitarios no sería compatible con un ideal republicano. Ahora bien, de aceptarse como válido el presupuesto hobbesiano sobre que la naturaleza del hombre es el egoísmo frente a sus pares, ${ }^{2}$ es acertado el cuestionamiento de la doctrina política sobre cuáles deberían ser las virtudes de los ciudadanos, y más problemático todavía, cuál sería el medio correcto para inculcarlos sin que el Estado adquiera un tinte autoritario.

Sobre la primera interrogante, los autores republicanos han descrito una serie de virtudes esenciales para el ciudadano de una república; no obstante, para efectos del presente escrito, únicamente se resaltará la condición que Quentin Skinner denomina como "prudencia para desempeñar un papel activo y efectivo en la vida pública" ${ }^{3} \mathrm{La}$ "prudencia" a la que se refiere el autor se encamina a proscribir cualquier conducta del ciudadano que vaya más allá de su rol público prestablecido, pues la consecuencia de un exceso conllevaría inexorablemente a un acto de corrupción.

Respecto de la interrogante referida al medio idóneo para inculcar la virtud de "prudencia" en el quehacer público, la doctrina se ha preguntado si es suficiente con que el Estado utilice los medios de socialización de información para propagar el mensaje cívico en los ciudadanos; de igual manera, se ha evaluado la legitimidad que tendría la práctica del Estado de sugestionar a los ciudadanos desde temprana edad para que introyecten los valores pretendidos; en fin, la discusión sobre el método más racional ha oscilado en diversas posturas sin que hayan podido superar la necesaria barrera de legitimidad e idoneidad. Por tanto, descartando cualquier otro medio estatal, se ha de sostener en la presente obra que la norma jurídica es el único medio suficiente y legítimo para cultivar el valor de "prudencia" en la actuación pública, puesto que la existencia misma de la norma ya impone un modelo de actuación acorde a los valores perseguidos para quienes tengan la posibilidad y capacidad de comprenderla.

1. Félix Ovejero, José Luis Martí y Roberto Gargarella, comps., Nuevas ideas republicanas: autogobierno y libertad (Barcelona: Paidós, 2004), 24. En el mismo sentido, Sunstein, sobre la importancia de la participación política de los ciudadanos, ha mencionado que esta no deberá efectuarse en un sentido meramente instrumental, sino que deberá entenderse como un canal para el ejercicio de la ciudadanía en donde primará la empatía, la virtud y el compromiso con el sentido de la comunidad. Véase, Cass Sunstein, "Más allá del resurgimiento republicano", en Nuevas ideas republicanas: autogobierno y libertad, comps. Félix Ovejero, José Luis Martí y Roberto Gargarella (Barcelona: Paidós, 2004), 160-1.

2. Thomas Hobbes, Leviatán (Ciudad de México: Cruz O., 1999), 148.

3. Quentin Skinner, "Las paradojas de la libertad política", en Nuevas ideas republicanas: autogobierno y libertad, comps. Félix Ovejero, José Luis Martí y Roberto Gargarella (Barcelona: Paidós, 2004), 107. 
Ahora bien, prima facie podría pensarse que la norma jurídica, al ser un medio coercitivo del que se vale el Estado para imponer valores republicanos, lesionaría la libertad y con ello la posibilidad de autodeterminación del ciudadano; pues, como bien pone de relieve Skinner parafraseando a Maquiavelo al decir que "es el hambre y la pobreza lo que vuelve trabajadores a los hombres, y son las leyes las que los vuelven buenos", ${ }^{4}$ parecería que inexorablemente el costo de una ciudadanía virtuosa se pagaría en moneda de la libertad de los mismos. Sin embargo, este argumento sería correcto siempre que dichas normas jurídicas tuvieran origen en un régimen absolutista, pero allí donde el origen de la ley sea democrático nada habría que objetar sobre su legitimidad.

Además, es indudable que la legitimidad de la norma jurídica respecto de la restricción a la libertad del ciudadano dependerá de la noción de "libertad" que se estime correcta. En ese sentido, la idea de libertad como no dominación es la que - a mi juicio- da en el clavo para justificar el hecho de que la ley no restringe arbitrariamente la libertad ${ }^{5}$. Así, por ejemplo, Santiago Truccone al referirse al ideal de libertad como no dominación prescribe lo siguiente:

La libertad como no dominación se garantiza cuando no hay posibilidad de interferirla arbitrariamente. Aún más, el republicanismo insiste en que la libertad queda restringida no solo por la interferencia fáctica o por la amenaza, sino también por el mero conocimiento de que estamos viviendo en dependencia de la buena voluntad de otros. ${ }^{6}$

Para cerrar este apartado, siempre que la norma tenga un origen democrático ${ }^{7}$ y esté encaminada a posibilitar la coexistencia y el próspero desarrollo de la comu-

4. Ibíd., 109.

5. Sobre esto, Pettit sostiene que: "bajo la concepción de la libertad como no-dominación, la dominación es necesaria y suficiente para una reducción de la libertad. Y eso significa que, si no hay dominación involucrada, la libertad no se reduce en presencia de interferencia o frustración. (...) Sugiere que, si las personas gobernadas por un estado controlan la interferencia practicada por el gobierno, si controlan las leyes impuestas, las políticas perseguidas, los impuestos aplicados, entonces no pueden sufrir la dominación a manos de sus gobernantes y pueden continuar disfrutando de sus responsabilidades". Philip Pettit, On the People's Terms. A Republican Theory and Model of Democracy (Nueva York: Cambridge, 2012), 152-3.

6. Santiago Truccone, "Delitos acumulativos ambientales: una aproximación desde el republicanismo", Revista de Derecho ambiental de la Universidad de Palermo, ISSN 2250-8120 (2013): 78.

7. El ideal democrático adoptado en el escrito es que a través de su ejercicio los ciudadanos se empapan de los asuntos políticos del gobierno, y de esa manera se ejerce una participación reflexiva sobre lo que resulta o no conveniente para el beneficio de la comunidad. En suma, cuando me refiero al control democrático de las normas jurídicas estoy pensando en un modelo de democracia deliberativa. Sobre esto, Roberto Gargarella, "Mano dura sobre el castigo. Autogobierno y comunidad (II)", Revista jurídica de la Universidad de Palermo (2015): 102, ha indicado: "De acuerdo con esta visión, en una democracia deliberativa, i) todos los potencialmente afectados por una cierta norma intervienen en su creación; ii) el proceso de 
nidad, su legitimidad no podrá ponerse en tela de duda. Asimismo, es loable pensar que no existe otro medio más idóneo que la Ley para asegurar el cumplimiento de ciertas obligaciones cívicas, puesto que esta ejerce una coerción necesaria mediante las eventuales consecuencias derivadas del incumplimiento. En suma, bajo los términos expuestos, tanto la obligación cívica de actuar con prudencia en la labor pública como también las consecuencias jurídicas que por su incumplimiento se desprendan gozarán de legitimidad política.

\section{DEBERES GENERALES Y ESPECIALES DE LOS CIUDADANOS DESDE LA PERSPECTIVA DEL DERECHO PENAL: UNA MIRADA ESPECIAL A LOS DELITOS DE CORRUPCIÓN}

Al ser válido el punto de partida en el sentido de que las normas jurídicas con origen democrático gozan de legitimidad, también habrá de aceptarse que los derechos y obligaciones que en dicha normativa se imponen a los ciudadanos deberán ser acatados. Por ello, la preocupación estatal de mantener un sistema de convivencia armónico se persigue a través de la regulación jurídica de la conducta de los ciudadanos. La regla general es que solo las infracciones más severas en contra del sistema de convivencia tengan un tratamiento desde la esfera jurídico-penal, puesto que para el resto de infracciones existen mecanismos jurídicos menos severos y más eficaces para la solución de controversias.

En este sentido, si nos situamos en un contexto en que resulta imperiosa la intervención del Derecho penal para regular y sancionar las conductas más lesivas para el sistema de convivencia, se debe notar que la gran mayoría de normas jurídico-penales están encaminadas a regular la conducta de la ciudadanía en general, ${ }^{8}$ pues la prohibición de matar, robar, lesionar, defraudar, etc., se encaminan a motivar a todos quienes transiten en un espacio geográfico determinado; sin embargo, es evidente que un número cerrado de normas se dirigen a regular la conducta de sujetos especialmente obligados en una esfera de atribución. Lo último puede constatarse con la tipificación

toma de decisiones que lleva a dicha creación se caracteriza fundamentalmente por una amplia discusión colectiva; y iii) organizada bajo condiciones de igualdad".

8. En este sentido, un sector de la doctrina sostiene lo que sigue: "la norma penal funciona protegiendo las condiciones elementales mínimas para la convivencia y motivando, al mismo tiempo, a los individuos que se abstengan de dañar esas condiciones elementales". Puede estudiarse en: Francisco Muñoz Conde y Mercedes García Arán, Derecho Penal. Parte General, 8 (Valencia: Tirant lo Blanch, 2010), 58. 
de infracciones de delicta propria ${ }^{9}$ en donde se requiere especiales características en el sujeto activo de la infracción para la configuración de un delito.

En esta inteligencia, el legislador, haciendo buen uso de sus atribuciones, ha tipificado ciertas conductas que según la doctrina jurídica pueden ser catalogadas como corruptas. Así, por ejemplo, en el Código Penal de la Nación Argentina puede encontrarse que se desvalora la conducta del funcionario público que en el ejercicio de sus funciones acepta un beneficio de carácter patrimonial para hacer o dejar de hacer un acto dentro de sus competencias (cohecho pasivo y activo), ${ }^{10} \mathrm{o} \mathrm{su} \mathrm{vez} \mathrm{se} \mathrm{prohíbe} \mathrm{que}$ los funcionarios públicos en razón de su cargo exijan cualquier beneficio patrimonial para ejecutar u omitir actuaciones (exacciones ilegales o concusión). ${ }^{11}$ Se tipifica además la desviación de fondos públicos (malversación, peculado), ${ }^{12}$ el incremento patrimonial injustificado (enriquecimiento ilícito), ${ }^{13} \mathrm{y}$ hasta el uso abusivo de la influencia originada del cargo público para obtener un acto que beneficie ilegítimamente ciertos intereses (oferta y tráfico de influencias), ${ }^{14}$ etc.; en fin, es claro que el legislador argentino está plenamente consciente de los deberes especiales que recaen sobre las personas que ejercen tareas vinculadas a la cosa pública, tal es el punto que incluso se habilita criminalizar la omisión de los funcionarios en razón de su posición de garantía frente al normal desarrollo de la administración.

Sobre lo último, con el objetivo de efectuar un parangón y sin la intención de desviarme del tema troncal, llama la atención la técnica legislativa en el Estado ecuatoriano, pues si bien se reconoce una especial gravedad a los delitos de corrupción, a la vez se deja abierta la puerta para facilitar la impunidad de los mismos, lo cual en nada se condice con los presupuestos de elevada rigidez en la prevención y control que exige el republicanismo para erradicar los actos de corrupción. El contexto es el siguiente: tanto la Constitución del Ecuador en el artículo $233^{15}$ como también el Código Orgáni-

9. Así, por ejemplo, Gómez Martin argumenta lo siguiente: "Los conceptos simples de delito especial se caracterizan por definirlo como aquella clase de tipo penal que se distingue porque en ellos se describe una conducta que solo es punible a título de autor si es realizada por ciertos sujetos que posean ciertas condiciones especiales que requiere la ley". Víctor Gómez Martin, Los delitos especiales (Madrid: EDISOFER, 2006), 15; con criterio semejante, véase: Eugenio Zaffaroni, Alejandro Alagia y Alejandro Slokar, Derecho penal. Parte general (Buenos Aires: Ediar, 2002), 788.

10. Carlos Creus, Derecho penal. Parte especial, tomo II, 6. ${ }^{\mathrm{a}}$ ed. (Buenos Aires: Astrea, 1998), 270.

11. Edgardo Donna, Derecho penal. Parte especial, tomo III (Buenos Aires: Rubinzal Culzoni, 2000$), 336$.

12. Ibíd., 285.

13. Ibíd., 364.

14. Ibíd., 229.

15. "Las servidoras o servidores públicos y los delegados o representantes a los cuerpos colegiados de las instituciones del Estado, estarán sujetos a las sanciones establecidas por delitos de peculado, cohecho, concusión y enriquecimiento ilícito. La acción para perseguirlos y las penas correspondientes serán imprescriptibles y, en estos casos, los juicios se iniciarán y continuarán incluso en ausencia de las personas 
co Integral Penal en el art. 16 núm. $4^{16}$ señalan la imprescriptibilidad de la acción y de la pena para los delitos de corrupción; asimismo, se ofrece la posibilidad de efectuar un juzgamiento en ausencia de los imputados; las penas privativas de libertad rondan desde los 3 hasta los 13 años sin tomar en cuenta las eventuales agravantes del caso; y, además, existen inhabilitaciones temporales para el ejercicio de cargos públicos y otras de carácter vitalicio como se da en el delito de peculado. ${ }^{17}$

Pero con lo expuesto parecería que existe una especial preocupación por el normal funcionamiento de la cosa pública, cumpliéndose a cabalidad la idea republicana de inculcar virtud cívica mediante la coerción de la norma jurídica; sin embargo, ha sido el mismo legislador quien se ha encargado de enviar un doble discurso a la ciudadanía, puesto que se desprende de la redacción de los tipos penales que solo se prevé la posibilidad de imputar el cohecho, la concusión y el tráfico de influencias a través de conductas de actividad y de omisión, es decir, sea que el funcionario por sí mismo (dominio del hecho) o por interpuesta persona (infracción del deber) cometa el delito de corrupción, de todas formas podrá ser imputado en calidad de autor por los mismos. Todo lo contrario sucede en el delito de peculado, pues, de cualquier forma que se interprete el art. 278 del COIP, este solo se puede cometer a través de una conducta de actividad, es decir, con dominio del hecho, y, en caso de que el funcionario público simplemente desatienda sus tareas y otro ejecute la conducta que atente contra los bienes del Estado, esto quedaría en la impunidad.

Dicha impunidad para los casos de peculado se reafirma aún más con el hecho de que no se ha sancionado una conducta imprudente y, además, se descarta la posibilidad de imputar actos de corrupción mediante conductas omisivas, pues, según el legislador ecuatoriano, en el marco del art. 28 referido a la omisión impropia, únicamente se encuentra en posición de garante la persona que tiene una obligación legal o contractual de custodia de los bienes jurídicos: "vida, salud, libertad e integridad personal del titular del bien jurídico y ha provocado o incrementado precedentemente un riesgo que resulte determinante en la afectación de un bien jurídico". ${ }^{18}$

acusadas. Estas normas también se aplicarán a quienes participen en estos delitos, aun cuando no tengan las calidades antes señaladas".

16. “Art. 16.- Ámbito temporal de aplicación.- (...) 4. Las infracciones de agresión a un Estado, genocidio, lesa humanidad, crímenes de guerra, desaparición forzada de personas, peculado, cohecho, concusión, enriquecimiento ilícito y las acciones legales por daños ambientales son imprescriptibles tanto en la acción como en la pena".

17. Puede revisarse en el art. 278 inciso final del Código Orgánico Integral Penal.

18. Puede estudiarse en: Ecuador, Código Orgánico Integral Penal, Registro oficial 180, 10 de febrero de 2014, art. 28 . 
Como puede verse, se ha prescrito expresamente que el funcionario no tiene un especial deber de protección del normal funcionamiento de la administración pública, o si se quiere del patrimonio del Estado, por lo que parece ser que el propósito republicano de inculcar virtud cívica en las tareas del ejercicio público no ha sido abrazado completamente por el legislador ecuatoriano. Había dicho, además, que proscribir la posibilidad de imputar delitos omisivos de corrupción, como el peculado, permitiría cierto grado de impunidad, pues dogmáticamente se advierten serios inconvenientes para una imputación de autoría en delitos especiales propios, en caso de prescribirse que solo pueden ser perpetrados mediante conductas de actividad, puesto que estas presuponen necesariamente un dominio sobre el curso lesivo. ${ }^{19}$ Veamos un ejemplo para entender la magnitud del problema:

El director del departamento financiero del Ministerio de Salud Pública en el Ecuador tiene como una de sus tareas controlar periódicamente que su equipo de trabajo distribuya los fondos públicos conforme ha sido establecido previamente en la planilla presupuestaria. Sin embargo, el día que le corresponde realizar el control decide no hacerlo por simple holgazanería; luego se advierte que los empleados a su custodia han estado desviando fondos públicos y se produce un serio perjuicio al Estado. En este contexto, para imputar la autoría en un delito de actividad se requiere necesariamente dominio sobre el curso lesivo; no obstante, puede verse que el director ni siquiera estuvo enterado de la mala administración de sus subalternos, por lo que tampoco existiría la posibilidad de imputarle complicidad o instigación. Para estos casos, como es evidente, se requiere la utilización de la estructura del delito omisivo impropio o a su vez de la teoría de la infracción del deber para poder imputarle responsabilidad penal, puesto que no es el dominio del hecho lo que fundamenta la autoría, sino la infracción al deber de controlar el correcto desarrollo de las actividades puestas a su cargo.

En fin, ya en el contexto jurídico argentino, hay que decir que bajo los presupuestos republicanos de "prudencia" en el ejercicio de tareas públicas, es entendible que los delitos de corrupción denoten una especial gravedad, pues no solo que las penas

19. Así, por ejemplo, Roxin sostiene que la teoría del dominio del hecho supone que el autor debe estar en las siguientes circunstancias: si realiza la acción típica personalmente (dominio de la acción); si hace ejecutar el hecho mediante otro cuya voluntad, según parámetros jurídicos, no es libre... (dominio de la voluntad); si presta en la fase ejecutiva una aportación al hecho funcionalmente significativa (dominio del hecho funcional). Claus Roxin, Autoría y dominio del hecho en el Derecho penal, 7. .a ed., trad. Joaquín Cuello Contreras y José Luis Serrano González de Murillo (Madrid: Marcial Pons, 1999), 337; véase también, Diego Manuel Luzón Peña, Lecciones de Derecho penal. Parte general, 3. . ed. (Valencia: Tirant lo Blanch, 2016), capítulo 12, parágrafo 27. 
tienen una entidad importante, sino que también acarrean inhabilitaciones ${ }^{20}$ para el ejercicio de funciones públicas y, más grave todavía, la declaratoria de imprescriptibilidad $^{21}$ de los mismos. Con esta decisión legislativa se pretende emitir un mensaje claro, pues se prolifera la idea de que un delito de corrupción no es como cualquier otro, incluso viene siendo igual o más grave que un delito contra la vida, a tal punto que el Estado se reserva la facultad de perseguir indefinidamente a quien haya cometido un acto de estas características.

Con todo lo dicho, bien podría cuestionar un funcionario que ha cometido un delito de peculado el por qué el Estado, luego de 15, 20, 25 años, todavía está facultado para perseguirlo penalmente, $\mathrm{y}$ en otros delitos especialmente graves como el narcotráfico o incluso delitos contra la vida existe una acotación temporal para criminalizarlos. Lo cierto es que dar una respuesta satisfactoria al cuestionamiento del funcionario corrupto resultaría complejo; sin embargo, se me ocurre que un buen argumento sería resaltarle la existencia de deberes especialísimos para quienes tengan a su cargo el normal desarrollo de la administración pública. Pero bien podría objetar el ciudadano corrupto y decir lo siguiente: ¿por qué constituye un deber especial velar por el normal desarrollo de la cosa pública y cuál sería el argumento para sostener que quitarle la vida a un semejante quebrantaría únicamente un deber general? Y no se me ocurre otra respuesta que explicarle sobre la existencia de intereses preponderantes, pues es evidente que, allí donde existan intereses políticos en juego, siempre habrá algunos de mayor importancia, y esto solo dependerá de la especificidad del contexto social, económico y de la ideología política adscrita. En este caso, siendo que la deshonesta administración pública conlleva una desestabilización de la estructura misma del Estado, y con ello se produciría un efecto dominó negativo en las demás esferas públicas, la especial gravedad de un suceso de esta naturaleza - pensando en términos republicanos- justificarían las decisiones legislativas que nuestro funcionario hipotético cuestiona.

20. Argentina, Código Penal de la Nación, LEY 11.179 (T.O.) 1984 actualizado, arts. 256 y siguientes.

21. Sobre este punto, Argentina Cámara Federal de Casación, "Sentencia", en Juicio n. ${ }^{\circ}$ 12099/1998/T01/12/ CFC8, carátula "Cossio, Ricardo Juan Alfredo y otros, recurso de casación", se ha resuelto en el sentido de que por aplicación directa del art. 36 de la Constitución Nacional resultan imprescriptibles los graves hechos de corrupción cometidos contra el Estado que conlleven enriquecimiento, pues estos atentarán contra el sistema democrático mismo. 


\section{TEORÍAS DE LA PENA: UNA FINALIDAD DEL CASTIGO COHERENTE CON EL REPUBLICANISMO}

Llegado a este punto, resulta de suma importancia destacar que, si la consecuencia jurídica más severa por el incumplimiento de los deberes generales y especiales que tenemos como ciudadanos de una república es la pena, habría que, en primer lugar, decantarse por una finalidad de la pena que vaya acorde con las ideas republicanas de un Estado. Se debe notar que la discusión sobre la finalidad del castigo es un tema que vuelve cíclicamente en el saber jurídico-penal; no obstante, un error frecuente en la doctrina es analizar las penas en abstracto, obviando las especificidades de cada una de ellas, por lo que para los efectos de la presente investigación se ha de poner el foco de atención únicamente en las penas privativas de libertad. Además, será relevante analizar la postura y propuesta de quienes se muestran renuentes a la imposición de esta clase de penas.

En este sentido, desde una visión en retrospectiva, se pone en evidencia que a lo largo de la producción académica se ha ideado una serie de teorías tendientes a justificar la imposición de la pena privativa de libertad. Desde la Ilustración, autores como Immanuel Kant (retribución en sentido moral) y Friedrich Hegel (retribución en sentido jurídico) han abogado por una teoría absoluta de la pena. Jescheck, por ejemplo, refiriéndose a la teoría defendida por Kant, indica que "la ley penal es un 'imperativo categórico' o, con otras palabras, un mandato de la justicia, libre de toda consideración final", 22 por tanto, el único fin de la pena bajo un ideal retributivo (moral) será la imposición de un castigo en razón de la infracción cometida sin que se preste atención al efecto que esta provoque en la sociedad. Con un argumento similar, Hegel — según la pluma de Roxin — sostiene que "el delito es la negación del Derecho y la pena como la negación de esta negación [...] y con ello el restablecimiento del derecho". ${ }^{23}$ En líneas generales, tanto Hegel como Kant concluyen que la pena privativa de libertad no debe perseguir finalidades intimidatorias ni correctivas, sino únicamente la imposición de un mal como consecuencia del quebrantamiento a la norma; sin embargo, el aporte fundamental que Hegel le da a la teoría retribucionista es que esta no debe entenderse como un castigo en términos de la "ley del Talión", sino como una equivalencia entre el delito y la pena, lo que ya supone introducir una

22. Hans Jescheck, Tratado de Derecho penal. Parte general, 4. ${ }^{a}$ ed., trad. José Luis Manzanares Samaniego (Granada: Comares, 1993), 61; en el mismo sentido, véase también: Mariano Silvestroni, Teoría constitucional del delito (Buenos Aires: Editores del Puerto, 2004), 26.

23. Claus Roxin, Derecho penal. Parte general, tomo I, trad. Diego Manuel Luzón Peña, Miguel Díaz y García Conlledo y Javier De Vicente Remesal (Madrid: Civitas, 2003), 83. También así lo resalta Santiago Mir Puig, Derecho penal. Parte general, 9. ${ }^{\mathrm{a}}$ ed. (Barcelona: Reppertor, 2011), 78. 
idea de responsabilidad solo en la medida de la culpabilidad por el hecho. A mi juicio, este último aporte reviste una importancia mayúscula pues encorseta la posibilidad de sancionar una conducta con penas desproporcionadas.

Por otro lado, existen teorías relativas que están encaminadas a la corrección del comportamiento de los ciudadanos; así, por ejemplo, Von Liszt sostenía que la teoría de la prevención especial consistía en el aseguramiento de la sociedad frente a los delincuentes, para lo cual era esencial que estos sean encerrados para intimidar al autor y de esa manera evitar que cometan delitos en el futuro, además se debía procurar su corrección durante el encierro para erradicar las reincidencias. ${ }^{24}$ No obstante, Liszt sostenía que el tratamiento que debía darse a los penados tenía que variar según las características del autor, lo cual supuso clasificar a los criminales de la siguiente forma: a) Corrección del delincuente capaz de corregirse y necesitado de corrección; b) Intimidación del delincuente que no requiere corrección; c) Inocuización del delincuente que carece de capacidad de corrección. ${ }^{25}$ La doctrina ha calificado a la teoría de Liszt como "prevención especial negativa", pues rondaba en sus presupuestos un argumento peligrosista que violaba expresamente el principio de Derecho penal de acto, nada diferente - a mi juicio - de los criterios aberrantes del positivismo criminológico de Lombroso, Ferri y Garófalo.

Ahora bien, la teoría de la prevención especial tuvo un reverdecer en la segunda mitad del siglo XX, sus idearios se alejaron de los criterios peyorativos con los que se clasificaba a los infractores y se centraron en un ideal resocializador. Sobre esto, Bacigalupo indica que la renovada prevención especial se caracteriza por un concepto pedagógico-social tendiente al tratamiento y eventual reincorporación del ciudadano a su comunidad, ${ }^{26}$ por ello, en tanto que ciudadanos de una comunidad, parece lógico seguir esta teoría que persigue la reincorporación de nuestros conciudadanos, pues constituye un deber cívico procurar la consolidación del pueblo.

El otro lado de la moneda en las teorías relativas es la concepción de prevención general. Antiguamente, Von Feuerbach desde un punto de partida contractualista sostenía que, al ser el principal objetivo del Estado la creación de condiciones jurídicas para la coexistencia de los ciudadanos, irremediablemente se tendrá que acudir a me-

24. Liszt, "Der Zweckgedanke im Strafrecht", ZStW 3 (1883), 1. citado en Roxin, ibíd., 87. Ese criterio preventivo especial también lo resalta y critica, Francisco Muñoz Conde, "Recensión: VORMBAUM, Thomas. Einführung in die moderne Strafrechtsgeschichte (introducción a la Moderna Historia del Derecho Penal)" (Polit. crim. n. ${ }^{\circ}$ 7, 2009), 10.

25. En Liszt, Strafrechtliche Vorträge und Aufsätze, tomo I, 1905, 166, citado en Enrique Bacigalupo, Derecho penal. Parte general, 2. ${ }^{a}$ ed. (Buenos Aires: Hammurabi, 1999), 35.

26. Ibíd., 36. 
dios coercitivos para lograr tal cometido.$^{27}$ Sobre la naturaleza de la prevención general de Feuerbach — dice Donna-, esta tiene como finalidad la intimidación de los ciudadanos que posiblemente quebranten alguna norma, además, persigue la aplicación efectiva de la sanción legal, puesto que, de no ser así, no habría tal intimidación. ${ }^{28} \mathrm{~A}$ raíz de la intimidación sobre el ciudadano que supone esta teoría, la doctrina la denominó prevención general negativa; y como reacción a esta, otro sector doctrinal sentó las bases de lo que supondría ser una teoría de la prevención general positiva. Rusconi por ejemplo, sostiene que su ideación debe ser atribuida al profesor Jakobs quien coloca el Derecho como instrumento de estabilización social. ${ }^{29}$ En suma, el eje central de esta teoría es que la pena tiene una función de ratificación y aseguramiento de la validez normativa sin la cual se quebrantaría el normal desarrollo de la vida social. ${ }^{30}$

Como es costumbre en el saber jurídico, cada una de las teorías que fueron descritas han sido fuertemente criticadas, por ejemplo: sobre las teorías absolutas se ha dicho que no es lógico servirse de una pena que prescinda por completo de fines sociales, puesto que, si el Derecho penal persigue la protección subsidiaria de bienes jurídicos, ${ }^{31}$ el ideal de protección —mediante la prevención — para lograr una convivencia pacífica sería inalcanzable si la pena no genera un efecto disuasorio en la sociedad. A lo sumo podría rescatarse - dice Roxin - la concepción de pena en la medida de la culpabilidad que se desprende de la retribución hegeliana, pero esta no sería suficiente pensando en los fines que el Derecho penal proclama. ${ }^{32}$

Por su parte, a las teorías de la prevención especial, tanto para la negativa como para la positiva (resocialización), de igual forma se le pueden efectuar algunas críti-

27. Anselm Von Feuerbach, Tratado de Derecho penal común vigente en Alemania (Buenos Aires: Hammurabi, 1989), 8; así también lo pone sobre la escena, Edmund Mezger, Derecho penal. Parte general (Buenos Aires: Editorial Bibliográfica Argentina, 1958), 371.

28. Edgardo Donna, Derecho penal. Parte general, tomo I (Santa Fe: Rubinzal Culzoni, 2006), 285.

29. Maximiliano Rusconi, Derecho penal. Parte general, 3. ${ }^{\mathrm{a}}$ ed. (Buenos Aires: Ad-Hoc, 2016), 74; véase, también, Günther Jakobs, Sobre la teoría de la pena, trad. Manuel Cancio Meliá (Bogotá: Universidad Externado de Colombia, 1998), 15.

30. Ibíd.

31. Sobre el objeto de protección del Derecho penal, en los últimos años se ha visto un incremento de la doctrina funcional sistémica que desplaza la noción de bien jurídico como objeto de protección del Derecho penal y a su vez centran el foco de atención en la protección de la norma jurídica como un valor indispensable para la sociedad. Sin embargo, la doctrina encaminada a proteger bienes jurídicos sigue siendo dominante. Así pues, pese a no ser funcionalista, Hans Welzel, Derecho penal. Parte general, trad. Fontán Balestra (Buenos Aires: Depalma, 1956), 3, sostenía que: "Sin embargo, la misión primaria del derecho penal no es el amparo actual de los bienes jurídicos; es decir, el amparo de la persona individual, de la propiedad, etc., pues es allí, precisamente, adonde, por regla general, llega su acción demasiado tarde. Por encima del amparo de los bienes jurídicos individuales concretos, está la misión de asegurar la validez real (la observancia) de los valores del actuar según el pensamiento jurídico".

32. Roxin, Derecho penal. Parte general, 84 . 
cas: a la teoría especial-negativa le aparecen críticas por donde se la mire, pues el solo hecho de pretender inocuizar a un ciudadano se estaría vulnerando el derecho a la dignidad humana, por lo que no debería ni siquiera tomarse en cuenta una teoría de estas características en un Estado democrático de Derecho; respecto de la especial-positiva, entiendo que sus presupuestos son válidos y legítimos pero su aplicación por sí sola carecería de consistencia, ya que, siendo su fundamento un ideal resocializador, no ofrecería resultados satisfactorios para los ciudadanos que no necesiten ser resocializados; esto puede suceder cuando estemos frente a conductas imprudentes o bien ante el perpetrador de un delito sumamente grave pero que dicha conducta sea absolutamente aislada según su correcto comportamiento mostrado a lo largo de su vida; bajo estas circunstancias, aquellos sujetos no podrían ser sancionados por no necesitar resocialización..$^{33}$ Además, no hay que obviar que la prevención especial-positiva está condicionada a su comprobación empírica, pues formalmente bien podría exaltarse las bondades de esta teoría encaminadas a reinsertar exitosamente a los penados, pero, si materialmente no es eficaz o, lo que es igual, no se traduce en un acortamiento de la reincidencia, sería una teoría obsoleta.

Sobre las teorías de la prevención general, de igual manera podría criticarse la concepción ideada por Feuerbach de que su aspiración de coacción psicológica mediante la norma carece de sustento empírico, ya que si el delincuente reflexionara sobre los costos y ventajas de su conducta antijurídica, ${ }^{34}$ aquello derivaría irremediablemente en una rebaja de las tasas delictivas, puesto que cualquier individuo con cinco dedos de frente se decantaría por el respeto a la norma y con ello mantener sus derechos como ciudadano. Podría objetarse también que tanto la prevención general negativa como también la positiva de Jakobs detonan en la imposibilidad de encorsetar las pretensiones punitivas desmedidas del Estado, en razón de que, si se arguye que "a mayor pena, mayor disuasión", se estaría legitimando la imposición de penas privativas de libertad draconianas que lesionarían frontalmente la dignidad del ser humano. ${ }^{35}$

33. Roxin, por ejemplo, se pregunta cómo va a justificarse desde un punto de vista de prevención especial, por ejemplo, el castigo de los delincuentes violentos del nacionalsocialismo que hoy en día son inofensivos y que viven en sociedad discretamente. Por lo que, según su entendimiento, la teoría preventivo-especial por sí sola no sería suficiente. Ibíd., 89.

34. En esta línea de pensamiento, Rawls parece compartir esta visión cuando dice: "el castigo funciona como una clase del sistema de precios: modificando los precios que uno tiene que pagar por el rendimiento de las acciones, se proporciona un motivo para evitar que se realicen ciertas acciones y para que se realicen otras". Citado en Gargarella, "Mano dura sobre el castigo. Autogobierno y comunidad (II)", 106.

35. Desde un enfoque filosófico, bien podría hacerse lugar a las críticas que efectuarían kantianos y hegelianos sobre que adoptar una tesis de disuasión supone la instrumentalización del ciudadano. Argumentos de esta índole pueden encontrarse en la obra Introducción a la metafisica de las costumbres de Kant, que ha sido aludida en la obra de Muñoz Conde y García Arán, Derecho penal. Parte general, 47, para criticar la prevención general negativa. 
Bien, expuestas que han sido las críticas y antes de tomar postura sobre cuál de las teorías de la pena resulta compatible con el ideal republicano, se estudiará la tesis de quienes argumentan sobre la posibilidad de prescindir de la antiquísima noción de castigo y adoptar un modelo más racional consecuente con los objetivos de ciudadanía republicana. En esta línea, Roberto Gargarella se pregunta lo siguiente: “¿Qué deberían decir los republicanos frente a un crimen cometido dentro de un contexto de integración legal, es decir, en una situación en donde las precondiciones de la responsabilidad delictiva se encuentran razonablemente satisfechas?". El autor argentino responde que la medida a adoptarse en ese contexto debe ser netamente inclusiva y orientada a la comunidad, lo que significaría una concepción comunicativa de la pena. ${ }^{36}$

Todo esto supone que los rasgos del reproche en términos republicanos de ninguna manera podrían direccionarse a la exclusión del ciudadano, pues esto reafirmaría y reproduciría los conflictos del individuo caído en la desgracia punitiva; para el republicanismo - dice Gargarella - lo peor que puede hacerse con los delincuentes es separarlos de aquellos que los quieren y les dan afecto, y "conectarlos" con otras personas que también han actuado de manera antijurídica, ${ }^{37}$ puesto que aquello únicamente alimentaría el delito. A todo esto, la alternativa puntual a la privación de libertad sería la concepción doctrinal de "justicia restaurativa", que en teoría devolvería el conflicto a las partes para que en una dinámica de diálogo y negociación se llegue a resolver los conflictos y pueda arribarse a una reconciliación. En el mismo sentido, Márquez tiene escrito que la justicia restaurativa "es una nueva manera de considerar a la justicia penal la cual se concentra en reparar el daño causado a las personas y a las relaciones más que en castigar a los delincuentes". ${ }^{38}$

En este punto, el lector podrá darse cuenta de que el problema no parece estar en las teorías que fundamentan la respuesta penal, sino en la manera de ejecutar las consecuencias jurídicas a raíz del quebrantamiento normativo. Sin embargo, para tomar postura sobre las teorías existentes, aquí se defenderá la idea de que las teorías de la pena analizadas de forma aislada no son suficientes por sí solas para justificar una pena privativa de libertad, pues, como se ha evidenciado en líneas anteriores, cada una de ellas adolece de imperfecciones. A mi juicio, la justificación de la pena debe conformarse por criterios de prevención general positiva, especial positiva, y estos a su vez deberán estar encorsetados por el principio de culpabilidad. ${ }^{39}$ No obstante,

36. Gargarella, "Mano dura sobre el castigo. Autogobierno y comunidad (II)", 105.

37. Ibíd., 108 .

38. Álvaro Márquez. "La justicia restaurativa versus la justicia retributiva en el contexto del sistema procesal de tendencia acusatoria". Prolegómenos. Derechos y valores 10, n. 20 (2007): 203.

39. Este ha sido el criterio defendido por Roxin en su tratado de Derecho penal y recientemente se ha reafirmado en el mismo en un paper; puede revisarse en Claus Roxin, "El nuevo desarrollo de la dogmática 
parece ser que la discusión troncal ronda el supuesto de si esta finalidad conglobada de la pena a la que me he adherido es reconciliable únicamente con la imposición de una pena privativa de la libertad o si, por el contrario, también puede dialogar armoniosamente con el ideal de justicia restaurativa en donde se aboga por la erradicación de las consecuencias restrictivas de la libertad. Veamos a continuación:

En términos de prevención general positiva no se avizora ningún inconveniente en aceptar esta última tesis, pues el mensaje que se enviaría a la ciudadanía sería el siguiente: "La norma jurídica está vigente y con ello se pretende proteger los bienes jurídicos del resto de ciudadanos, su incumplimiento tendrá consecuencias jurídicas pero no de carácter privativa de la libertad pues se ha demostrado empíricamente su inidoneidad; no obstante, sí habrá una consecuencia coercitiva que el ciudadano deberá cumplir para reparar y tratar de reestablecer en la medida de lo posible los efectos nocivos que se haya provocado". En términos de prevención especial positiva se vería reflejada aún más la consonancia, pues el Estado de una vez por todas dejaría la hipocresía de la idea de resocialización a través de medios que únicamente sirven para agravar el conflicto individual y social; la relación entre prevención especial positiva con la "justicia restaurativa" se daría bajo un ideal de racionalidad, pues el método para inculcar los valores propios de una comunidad republicana no estaría marcado por la violencia, miseria o disrupción familiar, propio de un modelo carcelario, sino en términos de respeto a la dignidad de los ciudadanos, procurando utilizar vías apropiadas para la solución de conflictos. Por último, como es lógico, únicamente se deberá adoptar procedimientos de "justicia restaurativa" cuando la conducta del ciudadano sea culpable de lesionar un bien jurídico.

Con todo lo argumentado, es claro que la finalidad del reproche estatal bajo presupuestos de prevención especial, general positiva y culpabilidad resultan ser ambivalentes, debido a que sirve para los supuestos en donde es factible utilizar un modelo de "justicia restaurativa" y además sirve para fundamentar los casos en donde inexorablemente se requiere la imposición de una pena privativa de libertad, pues sería caer en un peligroso romanticismo sostener que todos los delitos deben ser contrarrestados mediante un modelo de diálogo y negociación; lo cierto es que, ante delitos de especial gravedad como el terrorismo, genocidio y otras conductas semejantes, irremediablemente se deberá acudir al régimen de castigo que tanto cuestiona el ideal republicano; en este último supuesto, lo importante será abogar por la reformulación

jurídico-penal en Alemania”, trad. Ricardo Robles Planas e Ivó Coca Vila (Barcelona: InDret, 2012), 9; asimismo, uno de sus discípulos lo sigue en esta formulación, véase Joachim Rudolphi, "El fin del Derecho penal del Estado y las formas de imputación penal", en El sistema moderno del Derecho penal: cuestiones fundamentales (Madrid: Tecnos, 1991), 93. 
del actual sistema penitenciario plagado de malas prácticas y de esa manera reducir en la medida de lo posible las consecuencias perniciosas inherentes al encierro.

\section{CONCLUSIONES}

- Ser ciudadano de una república implica asumir un rol protagónico en los asuntos de carácter público, esto es un presupuesto necesario para vivir en democracia y asegurar la noción de autogobierno. Todo esto significa que un ciudadano gozará de tantas libertades como su participación pública le asegure; consecuentemente, un Estado no responderá a un papel estático, pues deberá procurar el establecimiento de un orden jurídico que asegure los derechos y obligaciones de sus habitantes, $\mathrm{y}$, siendo que la imposición de un régimen de comportamiento puede coartar la libertad individual, su legitimidad estará supeditada a cuán robusta sea la práctica democrática.

- La ciudadanía republicana trae implícita deberes generales y especiales para los ciudadanos, y estos se encuentran prescritos en las normas jurídicas. El incumplimiento de deberes generales y especiales que lesionan de peor manera los valores comunitarios tienen relevancia penal y la consecuencia jurídica más severa es la pena privativa de libertad.

- Los deberes generales de los ciudadanos aseguran, en lo principal, una convivencia pacífica y de respeto mutuo. Sin embargo, ante la imperiosa necesidad de resguardar ciertos aspectos troncales de la vida en comunidad, como por ejemplo la administración de la cosa pública, el legislador ha procurado imponer deberes especiales a quienes se desenvuelvan en este ámbito, pues se teme que una conducta que lesione el normal desenvolvimiento de dichas tareas podría menoscabar la estructura misma del Estado, acarreando un perjuicio para la comunidad en general. Consecuentemente, cualquier ciudadano que se muestre irreverente ante las normas especiales en el ámbito de la administración pública deberá ser catalogado como corrupto y, por ello, las consecuencias jurídicas son y deberán ser las más drásticas.

- La doctrina mayoritaria sobre la finalidad de la pena se decanta por adoptar un modelo mixto que tome en consideración la prevención especial positiva, prevención general positiva y el principio de culpabilidad. No obstante, estas teorías fundantes de la pena no están pensadas únicamente para justificar la pena privativa de libertad, sino que pueden dialogar armoniosamente con la idea de "justicia restaurativa" que se caracteriza por el diálogo y la conciliación entre las partes que han protagonizado el conflicto, y de esa manera buscar ponerles fin a las controversias, sin que sea necesario acudir a la nociva práctica del encarcelamiento. 
- Sin perjuicio de los beneficios que pueda traer consigo un modelo de "justicia restaurativa, no se debe dejar de notar que existen delitos de una gravedad mayúscula que afectan a la humanidad misma y, ante tales supuestos, la antiquísima y siempre cuestionada pena restrictiva de libertad será la única alternativa; el reto estará en identificar cuando estemos frente a uno y otro caso para adoptar las medidas acertadas.

\section{BIBLIOGRAFÍA}

\section{DOCTRINA}

Bacigalupo, Enrique. Derecho penal. Parte general, 2. ${ }^{a}$ ed. Buenos Aires: Hammurabi, 1999. Creus, Carlos. Derecho penal. Parte especial, tomo II, 6. ${ }^{a}$ ed. Buenos Aires: Astrea, 1998.

Donna, Edgardo. Derecho penal. Parte especial, tomo III. Buenos Aires: Rubinzal Culzoni, 2000.

-. Derecho penal. Parte general, tomo I. Santa Fe: Rubinzal Culzoni, 2006.

Feuerbach, Anselm Von. Tratado de Derecho penal común vigente en Alemania. Buenos Aires: Hammurabi, 1989.

Gargarella, Roberto. "Mano dura sobre el castigo. Autogobierno y comunidad (II)". Revista jurídica de la Universidad de Palermo (2015): 101-15.

Gómez Martin, Víctor. Los delitos especiales. Madrid: EDISOFER, 2006.

Hobbes, Thomas. Leviatán. Ciudad de México: Cruz O., 1999.

Jakobs, Günther. Sobre la teoría de la pena. Trad. Manuel Cancio Meliá. Bogotá: Universidad Externado de Colombia, 1998.

Jescheck, Hans. Tratado de Derecho penal. Parte general, 4. ${ }^{a}$ ed. Trad. José Luis Manzanares Samaniego. Granada: Comares, 1993.

Liszt, Franz Von. "Der Zweckgedanke im Strafrecht”, ZStW 3 (1883), 1, citado en Claus Roxin, Derecho penal. Parte general, tomo I. Trad. Diego Manuel Luzón Peña, Miguel Díaz y García Conlledo y Javier De Vicente Remesal. Madrid: Civitas, 2003.

-. Strafrechtliche Vorträge und Aufsätze, tomo I, 1905, citado en Enrique Bacigalupo, Derecho penal. Parte general, 2. ${ }^{\text {a }}$ ed. Buenos Aires: Hammurabi, 1999.

Luzón Peña, Diego Manuel. Lecciones de Derecho penal. Parte general, 3. ${ }^{a}$ ed. Valencia: Tirant lo Blanch, 2016.

Márquez, Álvaro. "La justicia restaurativa versus la justicia retributiva en el contexto del sistema procesal de tendencia acusatoria". Prolegómenos. Derechos y valores 10, n. 20 (2007): 201-12.

Mezger, Edmund. Derecho penal. Parte general. Buenos Aires: Editorial Bibliográfica Argentina, 1958.

Mir Puig, Santiago. Derecho penal. Parte general, 9. a ed. Barcelona: Reppertor, 2011.

Muñoz Conde, Francisco. "Recensión: VORMBAUM, Thomas. Einführung in die moderne Strafrechtsgeschichte (introducción a la Moderna Historia del Derecho Penal)". Revista Politica Criminal, n. 7 (2009): 1-16. 
Muñoz Conde, Francisco, y Mercedes García Arán. Derecho penal. Parte general, vol. 8. Valencia: Tirant lo Blanch, 2010.

Ovejero, Félix, José Luis Martí y Roberto Gargarella, comps., Nuevas ideas republicanas: autogobierno y libertad. Barcelona: Paidós, 2004.

Pettit, Philip. On the People's Terms. A Republican Theory and Model of Democracy. Nueva York: Cambridge, 2012.

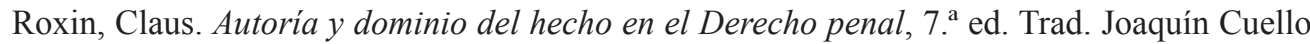
Contreras y José Luis Serrano González de Murillo. Madrid: Marcial Pons, 1999.

- Derecho penal. Parte general, tomo I. Trad. Diego Manuel Luzón Peña, Miguel Díaz y García Conlledo y Javier De Vicente Remesal. Madrid: Civitas, 2003.

—. "El nuevo desarrollo de la dogmática jurídico-penal en Alemania". Trad. Ricardo Robles Planas e Ivó Coca Vila. InDret, n. ${ }^{\circ}$ (2012).

Rudolphi, Joachim. "El fin del Derecho penal del Estado y las formas de imputación penal”. En El sistema moderno del Derecho penal: cuestiones fundamentales, coordinado por Bernd Schünemann y Jesús María Silva Sánchez, 81-93. Madrid: Tecnos, 1991.

Rusconi, Maximiliano. Derecho penal. Parte general, 3. ${ }^{a}$ ed. Buenos Aires: Ad-Hoc, 2016.

Silvestroni, Mariano, Teoría constitucional del delito. Buenos Aires: Editores del Puerto, 2004.

Skinner, Quentin. "Las paradojas de la libertad política”. En Nuevas ideas republicanas: autogobierno y libertad, compilado por Félix Ovejero, José Luis Martí y Roberto Gargarella, 93-114. Barcelona: Paidós, 2004.

Sunstein, Cass. "Más allá del resurgimiento republicano". En Nuevas ideas republicanas: autogobierno y libertad, compilado por Félix Ovejero, José Luis Martí y Roberto Gargarella, 137-90. Barcelona: Paidós, 2004.

Truccone, Santiago. "Delitos acumulativos ambientales: una aproximación desde el republicanismo". Revista de Derecho ambiental de la Universidad de Palermo (2013): 59-98.

Welzel, Hans. Derecho penal. Parte general. Trad. Fontán Balestra. Buenos Aires: Depalma, 1956.

Zaffaroni, Eugenio, Alejandro Alagia y Alejandro Slokar. Derecho penal. Parte general. Buenos Aires: Ediar, 2002.

\section{LEGISLACIÓN}

Argentina. Código Penal de la Nación, LEY 11.179 (T.O. 1984 actualizado).

Ecuador. Código Orgánico Integral Penal. Registro Oficial 180, 10 de febrero de 2014

-. Constitución de la República del Ecuador. Registro Oficial 449, 20 de octubre de 2009.

\section{Fallos Jurisprudenciales}

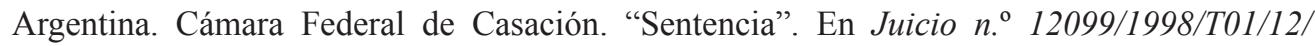
CFC8. 29 de agosto de 2018. 